\title{
Cholecystokinin-like activity in the duodenal mucosa of duodenal ulcer patients
}

\author{
S KATAOKA
}

From the Third Department of Medicine, Tohoku University School of Medicine, Sendai, Japan

SUMmARY Cholecystokinin-like activity in the duodenal mucosa was measured by the bioassay method described by Ljungberg ${ }^{1}$ to elucidate its significance in 14 duodenal ulcer patients as well as in 13 normal subjects with no evidence of gastrointestinal diseases. The stage of duodenal ulceration was determined endoscopically according to the criterion of the Japanese Gastroenterological Endoscopic Society. The cholecystokinin-like activity in the duodenal mucosa of duodenal ulcer patients in active stage 1, which was considered as an early stage of active open duodenal ulceration, did not differ statistically from that of normal subjects, whereas that of duodenal ulcer patients in active stage 2 began to show a significant increase $(p<0 \cdot 05)$, and the cholecystokinin-like activity in the duodenal mucosa of duodenal ulcer patients in healing stage 1 or healing stage 2 was significantly higher than that in normal subjects $(p>0.01)$. The cholecystokinin-like activity in the duodenal mucosa of duodenal ulcer patients in the scarring stage, however, returned to the normal range. It is concluded that cholecystokinin may act physiologically in the cure of duodenal ulcer.

Several articles have appeared on the kinetics of serum cholecystokinin-like immunoreactivity and on factors influencing this immunoreactivity - for example, acid or $\mathrm{H}_{2}$-receptor blockade - in duodenal ulcer patients. In order to clarify the significance of cholecystokinin in duodenal ulcer, it is also important to investigate the changes in cholecystokinin production in the duodenal mucosa and to ascertain the role of cholecystokinin in duodenal ulcer patients. We have previously found that cholecystokinin-like activity in the duodenal mucosa of these patients is significantly higher than that in normal subjects. ${ }^{23}$ This observation, however, was discussed in comparison with open ulcer and normal subjects so that the pathophysiological significance of cholecystokinin was somewhat uncertain. In order to determine the role of this substance in duodenal ulcer patients, we studied the kinetics of changes in cholecystokinin as they are related to the time-course of duodenal ulcer.

\section{Methods}

\section{SUBJECTS}

The cholecystokinin-like activity in the duodenal mucosa was studied in 14 duodenal ulcer patients

Received for publication 25 September 1981 and 13 normal subjects. The normal subjects, aged from 15 to 60 years (median, 40 years), were selected from outpatients in our hospital. All of them were interviewed, had a complete physical examination including a series of upper gastrointestinal tests, oral cholecystogram, pentagastrin-stimulated gastric analysis, upper gastrointestinal endoscopy, and some had a caerulein-secretin-stimulated pancreatic exocrine test, and were proved to be free of abnormalities. The duodenal ulcer patients, aged from 15 to 67 years (median, 37 years), were diagnosed by upper gastrointestinal radiography and endoscopy. All were free of severe complications of duodenal ulcer and were treated without $\mathrm{H}_{2}$ receptor blockades or hormone drugs.

The time-course of duodenal ulcer was divided into seven stages endoscopically according to the classification of the Japanese Gastroenterological Endoscopic Society ${ }^{4}$ (Table 1).

Cholecystokinin-like activity in the duodenal mucosa assayed included seven active cases in stage 1 , seven in active stage 2 , five in healing stage 1 , six in healing stage 2 , five in healing stage 3 , seven cases in the red scar stage, and five in the white scar stage.

BIOPSY OF DUODENAL MUCOSA

All subjects fasted for more than 12 hours before biopsy of the duodenal mucosa. After intramuscular 
Table 1 Stages of duodenal ulcer

\begin{tabular}{cl} 
Active stage \\
$\mathrm{A}_{1}$ & Fresh and deep ulcer with bleeding and thick coating at \\
& bottom and without any healing reaction \\
$\mathrm{A}_{2}$ & $\mathrm{~A}_{1}$ without bleeding \\
Healing stage & \\
$\mathrm{H}_{1}$ & Slightly diminished and shallower ulcer with conversion and \\
& reddening around the lesion \\
$\mathrm{H}_{2}$ & Healing ulcer with marked reddening and conversion and \\
& decreased white coating \\
$\mathrm{H}_{3}$ & Ulcer with only some white coating and erosion \\
$\mathrm{Scar}^{2}$ & \\
$\mathrm{~S}_{1}$ & Red scar \\
$\mathrm{S}_{2}$ & White scar \\
\hline
\end{tabular}

injection of $10 \mathrm{mg}$ scopolamine-butylbromide, a duodenofibrescope of JFB (Olympus) type was inserted into the second part of the subject's duodenum. Five to seven pieces of duodenal mucosa were obtained by forceps from the anterior and posterior walls at the same height as Vater's papillae.

\section{EXTRACTION OF CHOLECYSTOKININ}

The tissue specimens were placed into small lidded test tubes of polyethylene containing $450 \mu \mathrm{l} 0.01 \mathrm{~N}$ hydrochloride $(\mathrm{HCl})$, and were immediately heated in a dry bath at $100^{\circ} \mathrm{C}$ for three minutes in order to inactivate the proteolytic enzymes. After heating, 50 $\mu l 1.0 \mathrm{~N} \mathrm{HCl}$ was added to the tissue specimens, and they were preserved at $-20^{\circ} \mathrm{C}$ until cholecystokinin was isolated. In this procedure, the frozen tissue specimens were thawed at room temperature and well sonificated at $4^{\circ} \mathrm{C}$ for six minutes. The tissue specimens were then centrifuged at $10000 \mathrm{rpm}$ at $4^{\circ} \mathrm{C}$ and the supernatant obtained was used in the bioassay. The sediment was well dried at $37^{\circ} \mathrm{C}$ for 72 hours and was weighed to the order of $0.01 \mathrm{mg}$. The dry weight ranged from 0.8 to $1.5 \mathrm{mg}$.

For the number of biopsied materials mentioned above, the appropriate dose of cholecystokinin extracts for a single intravenous administration is in the range of 50 to $150 \mu \mathrm{l}$.

\section{ASSAY OF CHOLECYSTOKININ}

Male guinea-pigs of the Hartley strain, weighing 230 to $500 \mathrm{~g}$, were used in the bioassay. After an overnight fast, the animals were anaesthetised with $2 \mathrm{~g} / \mathrm{kg}$ urethane intraperitoneally.

Injections were made via a thin polyethylene tube (Clay Adams, USA) inserted into the jugular vein. A midline incision was made in the superior part of the abdominal wall. The gall bladder was lifted carefully and a thin thread sewn to its fundus. The thread was connected to a low friction frontal lever, coupled with a kymograph. Gall bladder movements were magnified approximately seven times on the kymograph. ${ }^{15}$

A standard dose response curve was obtained by using graded doses of caerulein, and cholecystokinin-like activity expressed by the dose of caerulein was converted into Ivy Dog Units per mg dry weight of duodenal mucosa. All samples were assayed in duplicate or triplicate.

\section{STATISTICAL ANALYSIS}

Seven mean cholecystokinin-like activities of duodenal ulcer patients from the onset to cure were compared with those obtained from normal subjects. Data were analysed by Student's $t$ test.

\section{Results}

\section{DOSE RESPONSE OF CONTRACTILE LENGTH OF}

GALL BLADDER TO STANDARD CHOLECYSTOKININ

\section{AND CAERULEIN}

Ninety-nine per cent pure cholecystokinin was administered intravenously in doses of $12 \cdot 5,25,50$, 100, 200, and 400 Ivy Dog Units 47 times in total, and the dose response curve was plotted by laying off the logarithmic dose along the horizontal axis and the contractile length of the gall bladder along the vertical axis, as shown in Fig. 1. As is clear from this Figure, there was a linear relationship between the logarithmic dose of cholecystokinin and the contractile length of the gall bladder.

The cholecystokinetic effects of caerulein were similar to that of cholecystokinin in the guinea-pig gall bladder tested in situ. The dose response curve of caerulein was parallel with that of $99 \%$ pure cholecystokinin (Fig. 1). According to the results shown in Fig. 1, $1 \mathrm{mg}$ caerulein was equivalent to 40000 Ivy Dog Units of $99 \%$ pure cholecystokinin, which is not in agreement with the findings in our previous reports. $^{23}$ This discrepancy might be due to the use of less pure cholecystokinin (Boots) in the earlier study. In the present study, therefore, highly purified cholecystokinin was used.

\section{SPECIFICITY}

Several substances which might cross-react with cholecystokinin in the bioassay system were tested. As far as is known, there are no substances, except caerulein, which compare with cholecystokinin in its stimulant action on the guinea-pig gall bladder. ${ }^{5} \mathrm{We}$ also tested the cholecystokinetic action induced by acetylcholine, histamine, prostaglandin, secretin, and gastrin. ${ }^{6}$ First, duodenal mucosal concentrations of these substances were estimated. For example, the duodenal mucosa contains acetylcholine at about $3.4 \mathrm{ng}$ per mg wet weight. ${ }^{78}$ This dose is equal to about $17 \cdot 0 \mathrm{ng}$ per mg dry weight, as 


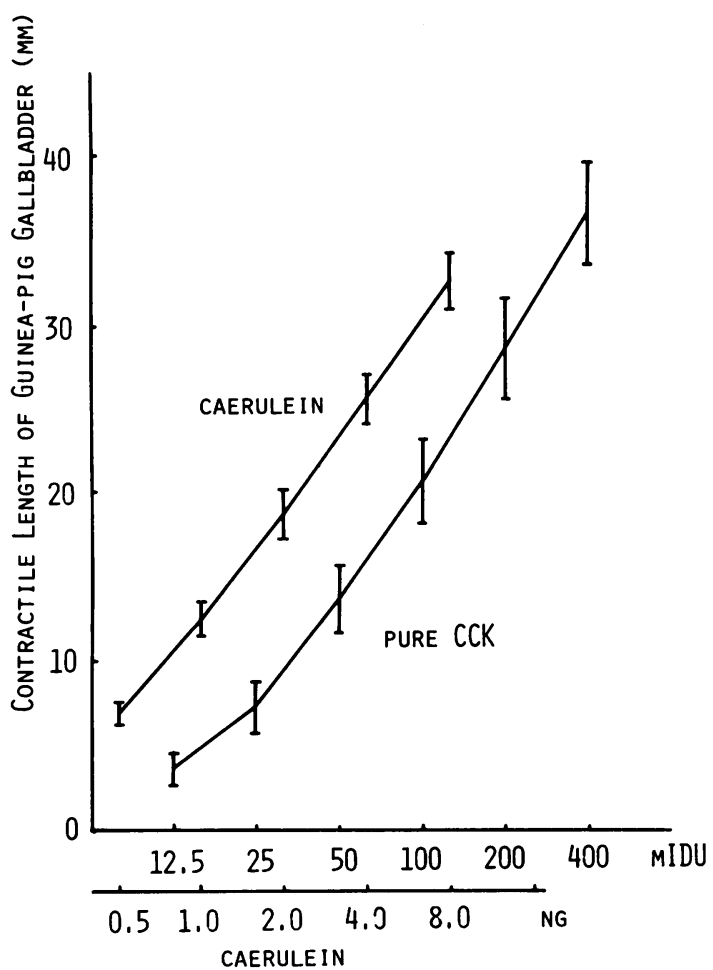

Fig. 1 Cholecystokinetic activities of caerulein and $99 \%$ pure cholecystokinin. Both show excellent dose response curves which run in parallel. As judged from these two cholecystokinetic activities, $1 \mathrm{mg}$ caerulein is equivalent to 40000 Ivy Dog Units of pure cholecystokinin.

wet weight is about five times dry weight. Our cholecystokinin extracts contain 13-30 ng of acetylcholine per $0.5 \mathrm{ml}$. As $50-150 \mu \mathrm{l}$ of cholecystokinin extracts were used for a single administration, the dose of acetylcholine contaminated in a single administration was at most $10 \mathrm{ng}$. Similarly, doses of histamine, ${ }^{9}$ serotonin, ${ }^{10}$ prostaglandin, ${ }^{11}$ secretin, ${ }^{12}$ and gastrin ${ }^{13}$ contaminated in a single administration were calculated, respectively. As is shown in Fig. 2, there is no cholecystokinetic action on the guinea-pig gall bladder induced by equal or more doses of acetylcholine (3-30 ng), histamine (1-100 $\mathrm{ng})$, serotonin $(0 \cdot 5-5 \mathrm{ng})$, secretin $(0 \cdot 05-0 \cdot 5$ $\mathrm{CHRu}$ ), or prostaglandin (10-100 $\mathrm{ng}$ ) as compared with the doses considered to be contaminated in a single administration, respectively. $125-500 \mathrm{pg}$ of pentagastrin, which is equivalent to the dose of gastrin contained in our extracts calculated by the same procedures described above, failed to induce a contraction of the gall bladder (Fig. 2). In addition, these substances interfered very little with the cholecystokinetic action of cholecystokinin.
The dose response curve using cholecystokinin extracts from the hog duodenal mucosa was parallel with that of pure cholecystokinin (Fig. 3). These findings proved that cholecystokinin-like activity assayed by means of the guinea-pig gallbladder is specific for cholecystokinin.

\section{RECOVERY EXPERIMENTS OF CHOLECYSTOKININ}

The recovery experiments by the method described above showed $85.5 \pm 4.7 \%$ recovery of added $99 \%$ pure cholecystokinin (mean \pm SEM). The cholecystokinin-like activity in extracts after three weeks and after thawing three times decreased only $3 \%$ as compared with the original bioactivity (Fig. 4). Thus the recovery rate of cholecystokinin from the duodenal mucosa is constant and the bioactivity is stable for at least three weeks. ${ }^{6}$ Therefore, all cholecystokinin-like activity of biopsied specimens was assayed in duplicate or triplicate within three weeks after cholecystokinin-extraction procedures.

\section{KINETICS OF CHOLECYSTOKININ-LIKE ACTIVITY IN} DUODENAL ULCER PATIENTS

The mean cholecystokinin-like activity in the duodenal mucosa in 13 normal subjects was $0.468 \pm 0.059$ Ivy Dog Units/mg dry weight expressed by mean \pm standard error of the mean.

The mean cholecystokinin-like activity in the duodenal mucosa of duodenal ulcer patients in active stage 1 was $0.312 \pm 0.046$ Ivy Dog Units/mg dry weight, which was not statistically different from that of the normal subjects. In contrast, the cholecystokinin-like activity in active stage 2 $(0.742 \pm 0 \cdot 111$ Ivy Dog Units/mg dry weight) started to show a significant increase $(p<0.05)$, and the cholecystokinin-like activity in healing stages 1 and 2 $(0 \cdot 860 \pm 0 \cdot 158$ and $0 \cdot 833 \pm 0 \cdot 117$ Ivy Dog Units/mg dry weight, respectively) was significantly higher than that in normal subjects (both $\mathrm{p}<0 \cdot 01$ ). However, the cholecystokinin-like activity in the duodenal mucosa in the red scar and white scar stages of duodenal ulcer patients $(0.474 \pm 0.053$ and $0.410 \pm 0.102$ Ivy Dog Units/mg dry weight, respectively) had returned to the normal range (Table 2, Fig. 5).

\section{Discussion}

In our earlier studies, we considered the possibility that raised cholecystokinin in the duodenal mucosa in duodenal ulcer patients might be a cause of the onset of duodenal ulcer because of similarities to gastrin in its experimental bioactivity and the amino acid structure at the active site. There were some patients, however, with open duodenal ulcer whose cholecystokinin-like activity in the duodenal mucosa 

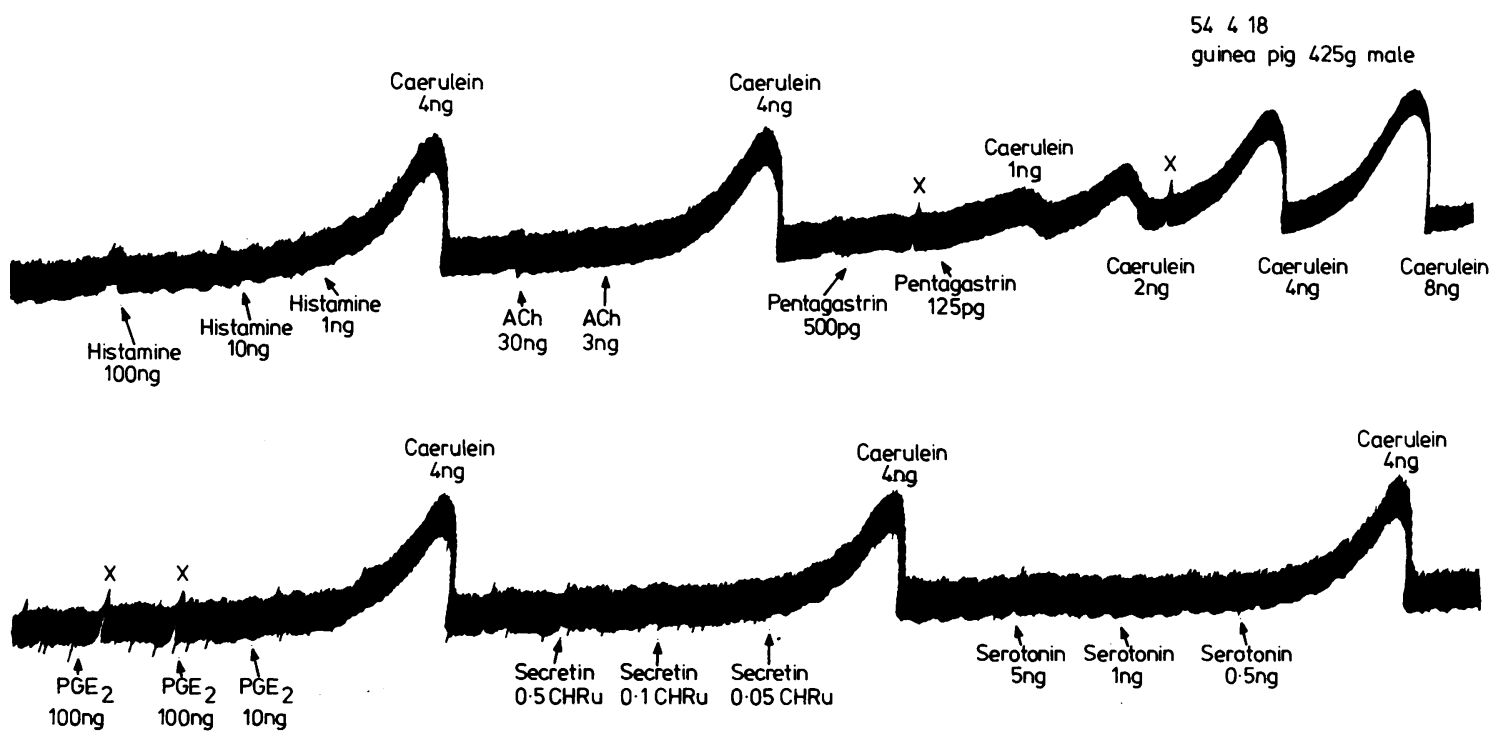

Fig. 2 Cholecystokinetic action of several substances contaminated in our cholecystokinin extracts. There is no cholecystokinetic action induced by acetylcholine (3-30 ng), histamine (1-100 ng), serotonin (0.5-5 ng), secretin (0.05-0.5 $C H R u$ ) and prostaglandin- $E_{2}(10-100 \mathrm{ng}) .125-500 \mathrm{pg}$ pentagastrin also failed to induce a contraction of gallbladder. $X$ denotes spike.

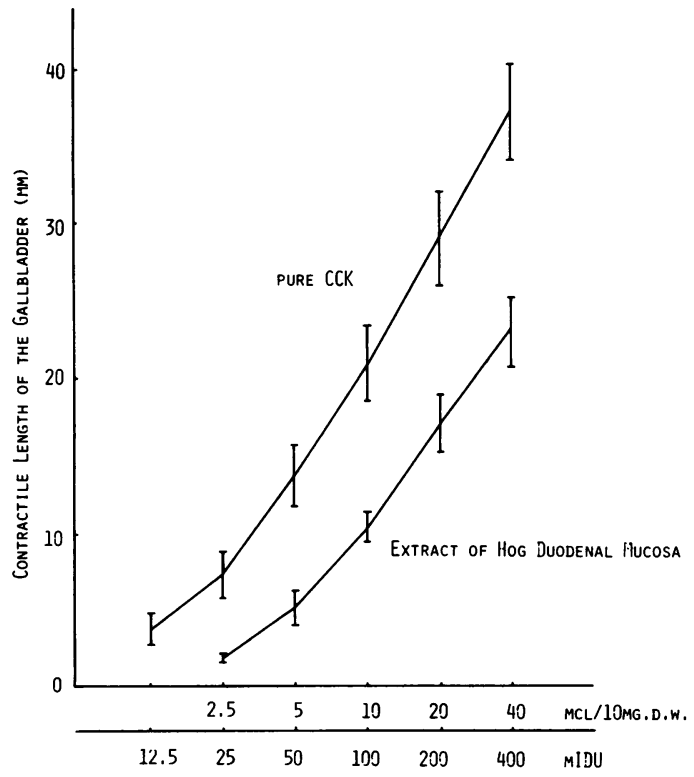

Fig. 3 Dose response curve of pure cholecystokinin and extracts of hog duodenal mucosa. Both show good dose response curves which run in parallel. As judged from these two cholecystokinetic activities, cholecystokinin-like activity assayed by mean of guineapig gall bladder is specific for cholecystokinin.

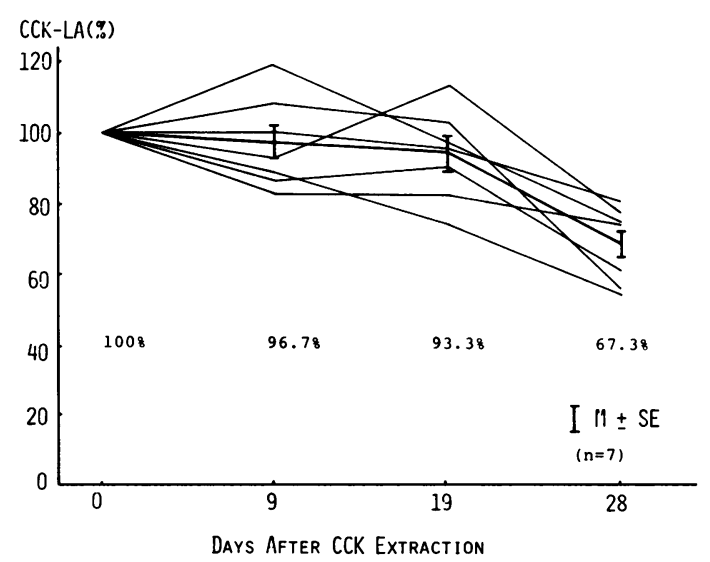

Fig. 4 Influences of thawing and storage at $-20^{\circ} \mathrm{C}$ upon cholecystokinetic activity of extracts. Percentage decrease of cholecystokinetic activity as compared with the original activity (expressed as 100\%) is less than $3 \%$ after 19 days and thawing three times. Cholecystokinetic activity is stable and constant within three weeks and tri-assays. 
Table 2 Cholecystokinin-like activity of duodenal mucosa as related to course of duodenal ulcer

\begin{tabular}{|c|c|c|c|c|c|c|c|c|c|}
\hline \multirow[b]{2}{*}{ Name } & \multirow{2}{*}{$\begin{array}{l}\text { Age } \\
\text { (yr) }\end{array}$} & \multirow[b]{2}{*}{$\operatorname{Sex}$} & \multicolumn{7}{|c|}{ Ivy Dog Unit per mg dry weight of duodenal ulcer } \\
\hline & & & $A_{1}$ & $A_{2}$ & $H_{I}$ & $\mathrm{H}_{2}$ & $\mathrm{H}_{3}$ & $S_{1}$ & $S_{2}$ \\
\hline KoS & 67 & $\mathbf{M}$ & & $1 \cdot 034$ & & & & $0 \cdot 379$ & \\
\hline $\mathrm{KeS}$ & 29 & $\mathbf{F}$ & & & 0.605 & 0.857 & 0.740 & & \\
\hline NT & 50 & $\mathbf{F}$ & 0.330 & & & $1 \cdot 088$ & & & \\
\hline KO & 63 & $\mathbf{M}$ & $0 \cdot 247$ & & & & 0.403 & $0 \cdot 242$ & $0 \cdot 171$ \\
\hline ES & 46 & $\mathbf{F}$ & & $1 \cdot 161$ & & & & 0.603 & \\
\hline HS & 36 & $\mathbf{M}$ & & & $1 \cdot 200$ & & & & 0.374 \\
\hline ET & 32 & $\mathbf{M}$ & & & $1 \cdot 286$ & & & $0 \cdot 390$ & 0.673 \\
\hline JI & 26 & $\mathbf{M}$ & & 0.738 & & $1 \cdot 223$ & & 0.574 & \\
\hline TK & 41 & $\mathbf{M}$ & & 0.722 & & & 1.000 & & \\
\hline UM & 27 & $\mathbf{M}$ & 0.366 & 0.413 & & 0.732 & & 0.525 & \\
\hline TI & 15 & $\mathbf{M}$ & 0.239 & 0.771 & & & & 0.608 & \\
\hline MO & 25 & $\mathbf{M}$ & 0.400 & & 0.667 & 0.595 & 0.400 & & \\
\hline SA & 27 & $\mathbf{M}$ & 0.486 & & 0.543 & & 0.644 & & 0.618 \\
\hline TH & 32 & $\mathbf{M}$ & 0.114 & 0.353 & & 0.494 & & & $0 \cdot 214$ \\
\hline n & 14 & & 7 & 7 & 5 & 6 & 5 & 7 & 5 \\
\hline Mean & 37 & & $0 \cdot 312$ & $0 \cdot 742$ & 0.860 & 0.833 & 0.637 & 0.474 & 0.410 \\
\hline SD & & & 0.122 & 0.295 & 0.353 & 0.285 & $0 \cdot 252$ & $0 \cdot 140$ & 0.229 \\
\hline SE & & & 0.046 & 0.111 & $0 \cdot 158$ & 0.117 & $0 \cdot 113$ & 0.053 & $0 \cdot 102$ \\
\hline
\end{tabular}

$A_{1}$ : active stage $1 ; A_{2}$ : active stage $2 ; H_{1}$ : healing stage $1 ; H_{2}$ : healing stage $2 ; H_{3}$ : healing stage $3 ; S_{1}$ : red scar; $S_{2}$ : white scar.

was not raised as compared with that in normal subjects. Classifying the features of duodenal ulcer endoscopically, all of them were proved fresh and deep duodenal ulcers without any healing reaction. Other patients, whose cholecystokinin-like activity in the duodenal mucosa was raised as compared with that in normal subjects, were recognised as having healing duodenal lesions. The possibility that raised cholecystokinin-like activity in the duodenal mucosa

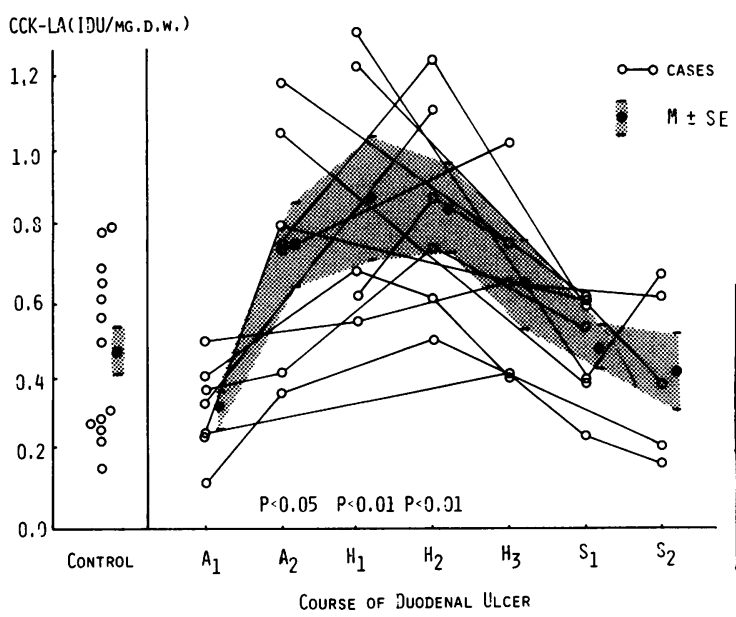

Fig. 5 Cholecystokinin-levels in duodenal mucosa as related to course of duodenal ulcer. was a cause of onset of duodenal ulcer became unacceptable. In order to clarify the significance of cholecystokinin in duodenal ulcer patients, an examination was needed which aimed to clarify the kinetics of the level of cholecystokinin in the duodenal mucosa as related to the time-course of duodenal ulcer. In the present paper, duodenal mucosa was biopsied two or more times in 14 duodenal ulcer patients in different stages of the disorder. Results showed that the cholecystokinin-like activity in the scarring stages did not differ statistically from that in normal subjects. The activity in active stage 1 was slightly decreased as compared with that in normal subjects $(0.05<p<0 \cdot 1)$. This finding suggests that a.decrease in the level of cholecystokinin in the duodenal mucosa (or an increase in cholecystokinin secretion) may play a part in the onset of duodenal ulcer formation.

On the other hand, cholecystokinin-like activity in the duodenal mucosa of duodenal ulcer patients in active stage 2 and healing stages 1 and 2 was significantly higher than that in normal subjects. The significance of this raised activity in the duodenal mucosa is as yet uncertain. The fact that cholecystokinin-like activity in duodenal ulcer patients showed a similar temporal pattern, as related to the timecourse of duodenal ulcer reaching a peak at the healing stage, suggests the possibility that raised production of cholecystokinin in the duodenal mucosa (or decreased cholecystokinin secretion) 
plays a role in the cure of duodenal ulcer. The basal serum level of cholecystokinin immunoreactivity in duodenal ulcer patients, however, did not differ from that in normal subjects and the amount of cholecystokinin secreted in duodenal ulcer patients after a test meal was not less than that in normal subjects. ${ }^{14}$ Therefore, raised cholecystokinin-like activity in the duodenal mucosa in duodenal ulcer patients was due to increased cholecystokinin production but not to its decreased secretion. As far as is known, cholecystokinin has many actions on the gastroenteropancreatic system, many of which may facilitate the healing of duodenal ulcer. For example, cholecystokinin inhibits gastric secretion, facilitates Brunner's gland secretion, increases pancreatic bicarbonate secretion, and seems to have trophic effects on the duodenal mucosa. ${ }^{15} 16 \mathrm{We}$ therefore considered that raised cholecystokinin-levels in the duodenal mucosa might act physiologically on the cure of duodenal ulcer.

The mechanism of hyperproduction of cholecystokinin in the duodenal mucosa after onset of duodenal ulcer is not clear either. The possibility that duodenal lesions might reduce the rate of cholecystokinin secretion was rejected as described above. It seems unlikely that duodenal lesions could stimulate the rate of synthesis of cholecystokinin in the duodenal mucosa, as we have found that duodenitis does not influence cholecystokinin-like activity in the duodenal mucosa (unpublished data). The idea that imbalance of gastrointestinal hormones caused by duodenal lesion increases this activity in the duodenal mucosa is unlikely, too, because gastrin ${ }^{17}$ did not change as greatly as cholecystokinin in the present report and secretin was sometimes slightly decreased ${ }^{18}$ and sometimes increased $^{12}$ - that is, there was not always agreement on the results of the level of duodenal mucosal secretin. In the end, the mechanism of hyperproduction of cholecystokinin in the duodenal mucosa after onset of duodenal ulcer remains unclear.

Spence and his coworkers ${ }^{19}$ found that fasting serum levels of cholecystokinin fell after $\mathrm{H}_{2^{-}}$ receptor blockade for two months in chronic duodenal ulcer patients. They noted that, among the most likely possibilities, metiamide might reduce the basal rate of cholecystokinin secretion. In our experiments, however, cholecystokinin-like activity in the duodenal mucosa fell in healing stage 3 and scarring stages without $\mathrm{H}_{2}$-receptor blockade. Therefore, there might be no reduction in the rate of cholecystokinin secretion by $\mathrm{H}_{2}$-receptor blockade, though there is reduction in the rate of gastric acid secretion. Indeed, the relationship between cholecystokinin and gastric acid may be important.
However, gastric acid in duodenal ulcer patients, as discussed by Bochus, ${ }^{20}$ did not vary considerably with the time-course of duodenal ulcer. As shown in Fig. 6, basal acid output was not changed essentially and maximal acid output was slightly but not significantly decreased in our patients, too. Additionally, there was no statistically significant correlation between the two parameters when gastric acid secretion was plotted against cholecystokinin-like activity in the duodenal mucosa in duodenal ulcer patients (Fig. 7). So gastric acid probably does not exert an important effect upon the production and secretion of cholecystokinin. We, therefore, believe that metiamide, which decreases the gastric output in duodenal ulcer patients, may not affect cholecystokinin production and secretion in the duodenal mucosa.

Abnormal timing in cholecystokinin secretion has been described in duodenal ulcer patients. ${ }^{16}$ The abnormality has not yet been sufficiently documented, but Harvey ${ }^{21}$ suggested that abnormalities in the rate of gastric emptying and of small intestinal transit might affect the pattern of cholecystokinin secretion. Additionally, raised cholecystokinin-like

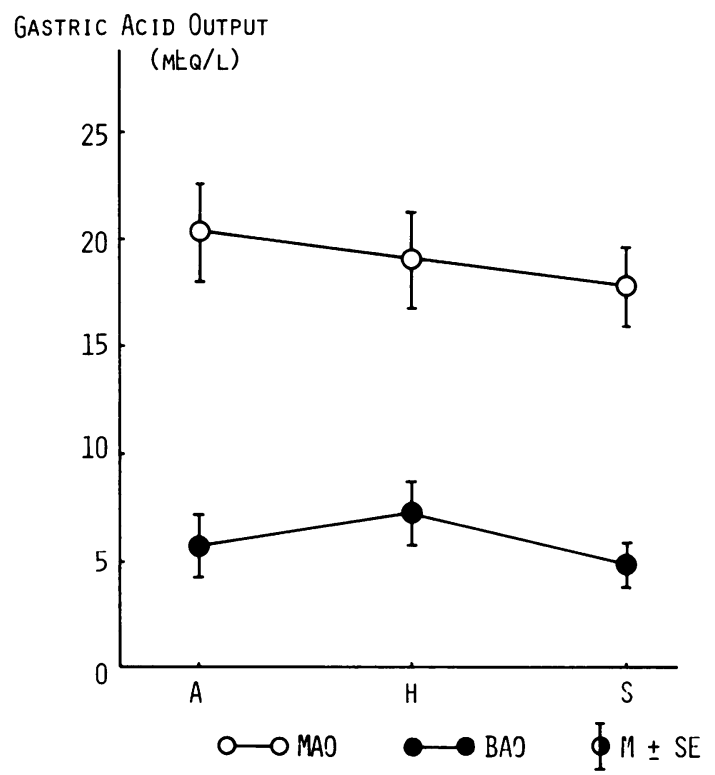

$$
\begin{aligned}
& \text { A: Active Stage } \\
& \text { H: Healing Stage } \\
& \text { S: Scarring Stage }
\end{aligned}
$$

Fig. 6 Change of $B A O$ and $M A O$ as related to time-course of duodenal ulcer. $B A O$ was not changed and $M A O$ was slightly but not significantly decreased. A: active stage. $H$ : healing stage. S: scarring stage (see Table 1). BAO: basal acid output. MAO: maximal acid output. 

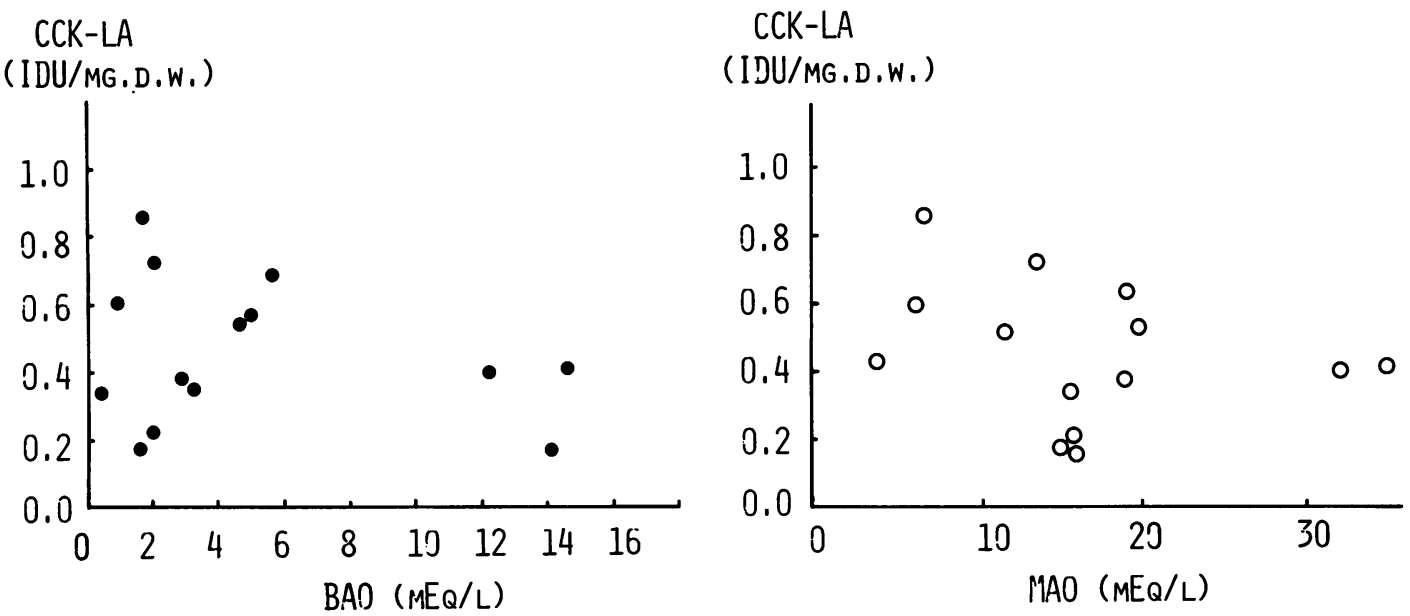

Fig. 7 Cholecystokinin-like activity and gastric analysis. There was no correlation between cholecystokinin-like activity and basal acid output or maximal acid output. These outputs were calculated as total acid output for 60 minutes before and after intramuscular injection of tetragastrin $10 \mu \mathrm{g} / \mathrm{kg}$ body weight.

activity in the duodenal mucosa in duodenal ulcer patients may play a part in the production of a rapid and sharp rise in serum cholecystokinin levels after food intake.

In conclusion, judging from the above results and a review of the relevant literature, we concluded that cholecystokinin might act physiologically on the cure of duodenal ulcer. The gastric acid in duodenal ulcer patients probably does not exert an important effect upon the kinetics of cholecystokinin. Further studies on, for example, the direct trophic action of cholecystokinin on the duodenum are needed.

The author would like to thank Professor Y Goto and Professor M Ishikawa for their help. He would also like to thank Dr S Tachibana for his advice on bioassay and for supplying pure cholecystokinin.

\section{References}

1 Ljungberg S. Biologik styrkebestamning av cholecystokinin. Svensk Farmaceut Tidskr 1964; 68: 351-2.

2 Kataoka S, Kamei T, Ishikawa, M. Bioassay of cholecystokinin-pancreozymin in duodenal mucosa. Lancet 1978; 1: 1043.

3 Kataoka S, Kamei T, Ishikawa M. Bioassay of cholecystokinin in the duodenal mucosa. Gastroenterol Jpn 1978; 13: 239-43.

4 Mori S. Endoscopical diagnosis of duodenal ulcer. In: Takemoto T, Kawai K, eds. Topics of gastroenterological endoscopic examination. Tokyo: Igaku Shuppan, 1978: 247-52. (In Japanese).
5 Bertaccini G, De Cargo G, Endean R, Erspamer V, Impicciatore $M$. The action of caerulein on the smooth muscle of the gastrointestinal tract and the gallbladder. Br J Pharmacol 1968; 34: 291-310.

6 Kataoka S, Kamei T, Takebe T. Studies on bioassay of cholecystokinin-like activity in the duodenal mucosa. The biliary tract and pancreas. 1980; 1: 1538-44. (In Japanese).

7 Yagasaki O, Kagawa K, Takewaki T, Yanagiya I. A method for differential measurement of free and bound acetylcholine in the small intestine. Japan J Pharmacol 1972; 22: 425-6.

8 Takewaki T, Yagasaki O, Yanagiya I. Changes of tissue acetylcholine in the distended intestine. Japan $J$ Pharmacol 1975; 25: 223-32.

9 Stone JL, Merrill JM, Meneely GR. Distribution of histamine in human tissues. Fed Proc 1955; 14: 147-8.

10 Garattini S, Valzelli L. In: Garattini S, Valzelli eds. Serotonin. Amsterdam: Elsevier, 1965: 241.

11 Piper PJ. In: Cuthbert MF, ed. The prostaglandins. London: Heinemann, 1973: 125.

12 Takebe $\mathrm{T}$, Ishizuki S, Kagaya $\mathrm{T}$ et al. Secretin-like bioactivity in the duodenal mucosa in patients with peptic ulcer and chronic pancreatitis. Tohoku J Exp Med 1978; 126: 13-26.

13 Rehfeld JF, Stadfil F, Malmstrom J et al. Gastrin heterogeneity in serum and tissue. A progress report. In: Thompson JC, ed. Gastrointestinal hormones. Austin: University of Texas Press, 1975: 43-51.

14 Rayford PL, Fender HR, Ramus NI, Reeder DD, Thompson JC. Release and half time of CCK in man. In: Thompson JC ed. Gastrointestinal hormones. Austin: University of Texas Press, 1975: 301-18.

15 Rayford PL, Miller TA, Thompson JC. Secretin; cholecystokinin and newer gastrointestinal hormones (First of two parts). $N$ Engl J Med 1975; 294: 1093-01. 
16 Johnson LR. The trophic action of gastrointestinal hormones. Gastroenterology 1976; 70: 278-88.

17 Hayes JR, Ardill J, Buchanan KD. Gastrin in duodenal ulceration. In: Bloom SR, ed. Gut hormones. Edinburgh: Churchill Livingstone, 1978: 624-6.

18 Koizumi F, Ishimori A, Nakanome C, et al. Mucosal secretin of the duodenum in peptic ulcer disease. Tohoku J Exp Med 1981; 133: 301-5.

19 Spence RW, Celestin LR, Harvey RF. Effect of metiamide on basal and stimulated serum cholecystokinin levels in duodenal ulcer patients. Gut 1976; 17: 920-3.

20 Bochus HL. Gastric analysis and cytologic examination. In: Bochus HL, ed. Gastroenterology. Philadelphia: Sanders, 1963: vol 1: 499-503.

21 Harvey RF. Pathology of cholecystokinin in man. In: Bloom SR, ed. Gut hormones. Edinburgh: Churchill Livingstone, 1978: 219-33. 